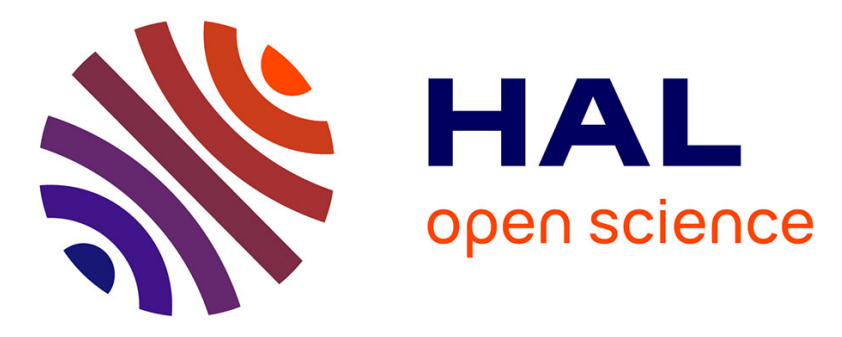

\title{
Oxaliplatin sensitizes human colon cancer cells to TRAIL through JNK-dependent phosphorylation of Bcl-xL.
}

Zineb El Fajoui, Florent Toscano, Guillaume Jacquemin, Jacques Abello, Jean-Yves Scoazec, Olivier Micheau, Jean-Christophe Saurin

\section{To cite this version:}

Zineb El Fajoui, Florent Toscano, Guillaume Jacquemin, Jacques Abello, Jean-Yves Scoazec, et al.. Oxaliplatin sensitizes human colon cancer cells to TRAIL through JNK-dependent phosphorylation of Bcl-xL.. Gastroenterology, 2011, 141 (2), pp.663-73. 10.1053/j.gastro.2011.04.055 . inserm-00626618

\section{HAL Id: inserm-00626618 https://www.hal.inserm.fr/inserm-00626618}

Submitted on 26 Sep 2011

HAL is a multi-disciplinary open access archive for the deposit and dissemination of scientific research documents, whether they are published or not. The documents may come from teaching and research institutions in France or abroad, or from public or private research centers.
L'archive ouverte pluridisciplinaire HAL, est destinée au dépôt et à la diffusion de documents scientifiques de niveau recherche, publiés ou non, émanant des établissements d'enseignement et de recherche français ou étrangers, des laboratoires publics ou privés. 


\title{
AQ:-1:3 Oxaliplatin Sensitizes Human Colon Cancer Cells to TRAIL Through JNK- Dependent Phosphorylation of Bcl-xL
}

\author{
ZINEB EL FAJOUI, ${ }^{\star}$ FLORENT TOSCANO, ${ }^{\ddagger}$ GUILLAUME JACQUEMIN,,,$\|$ JACQUES ABELLO, , JEAN-YVES SCOAZEC, ${ }^{*}$ \\ OLIVIER MICHEAU, \$,\|, and JEAN-CHRISTOPHE SAURIN*
}

AQ: 4 *INSERM U865, University of Lyon, Faculté Laënnec, Lyon, France; ¥ UMR1052 CNRS 5286, Centre de Recherche en Cancérologie de Lyon, University of Lyon,

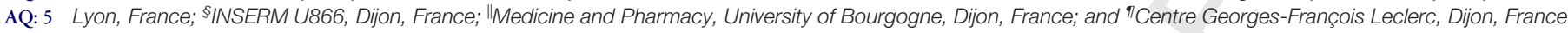

AQ: 14 BACKGROUND \& AIMS: Oxaliplatin sensitizes drug-resistant colon cancer cell lines to tumor necrosis factorrelated apoptosis inducing ligand (TRAIL), a death receptor ligand that is selective for cancer cells. We investigated the molecular mechanisms by which oxaliplatin sensitizes cancer cells to TRAIL-induced apoptosis. METHODS: We incubated the colon cancer cell lines HT29 and V9P, which are resistant to TRAIL, with TRAIL or with oxaliplatin for 2 hours, followed by TRAIL. Annexin V staining was used to measure apoptosis; RNA silencing and immunoblot experiments were used to study the roles of apoptosis-related proteins. Site-directed mutagenesis experiments were used to AQ: 15 determine requirements for phosphorylation of Bcl-xL; coimmunoprecipitation experiments were used to analyze the interactions among Bcl-xL, Bax, and Bak, and activation of Bax. RESULTS: Oxaliplatin-induced sensitivity to TRAIL required activation of the mitochondrial apoptotic pathway; reduced expression of Bax, Bak, and caspase- 9 , and stable overexpression of $\mathrm{Bcl}-\mathrm{xL}$, reduced TRAIL-induced death of cells incubated with oxaliplatin. Mitochondrial priming was induced in cells that were sensitized by oxaliplatin and required signaling via c-Jun $\mathrm{N}$-terminal kinase and phosphorylation of Bcl-xL. Mimicking constitutive phosphorylation of Bcl-xL by site-directed mutagenesis at serine 62 restored sensitivity of cells to TRAIL. Co-immunoprecipitation experiments showed that oxaliplatin-induced phosphorylation of Bcl-xL disrupted its ability to sequestrate Bax, allowing Bax to interact with Bak to induce TRAIL-mediated apoptosis. CONCLUSIONS: Oxaliplatin facilitates TRAIL-induced apoptosis in colon cancer cells by activating c-Jun $\mathrm{N}$-terminal kinase signaling and phosphorylation of Bcl-xL. Oxaliplatin-induced sensitivity to TRAIL might be developed as an approach to cancer therapy.

Keywords: Chemotherapy; Cell Death; Kinase; Colorectal Cancer Therapy.

$\mathrm{C}$ olon cancer is the second leading cause of cancerrelated deaths in Western countries. Chemotherapy is the treatment of choice for patients with recurrent colon tumors, but despite the introduction of several novel anticancer agents, almost $50 \%$ of patients die because of disease progression. It is therefore of interest to develop new therapeutic strategies.

Tumor necrosis factor-related apoptosis-inducing ligand (TRAIL) is a promising anticancer agent because of its ability to induce apoptosis selectively in cancer cells. ${ }^{1}$ TRAIL binds to the cell surface death receptors (DR) 4 and DR5 to trigger the extrinsic apoptotic pathway, mainly through the activation of the pro-apoptotic initiator caspase- $8 .^{2}$ In type I cells, active caspase- 8 induces the cleavage of the downstream effector caspase-3, which ultimately leads to apoptosis. ${ }^{3}$ By contrast, in type II cells, apoptosis requires an amplification loop, generally afforded by the intrinsic (mitochondrial) cell death pathway. ${ }^{4}$ This pathway is tightly regulated by the $\mathrm{Bcl}-2$ family through complex interactions that dictate the integrity of the outer mitochondrial membrane. ${ }^{5}$ The BH3-only pro-apoptotic proteins (Bid, Bad, Bim, Noxa, Puma, and so forth) act as initiators of the intrinsic apoptotic pathway, whereas the multidomain pro-apoptotic proteins Bax and Bak act as essential mediators of mitochondrial permeability. ${ }^{5}$ The anti-apoptotic $\mathrm{Bcl}-2$ family proteins (Bcl-2, Bcl-xL, and $\mathrm{Mcl}-1)$ inhibit apoptosis by binding to these pro-apoptotic members, thus neutralizing their activity. Overexpression of anti-apoptotic $\mathrm{Bcl}-2$ family proteins is one of the major causes of TRAIL resistance. ${ }^{6}$ The function of Bcl-xL can be regulated by transcriptional control and/or post-transcriptional modifications. Emerging evidence indicates that Bcl-xL phosphorylation may regulate its antiapoptotic functions. Multiple kinases, including c-Jun N-terminal kinase (JNK), have been proposed to mediate the phosphorylation of $\mathrm{Bcl}-\mathrm{xL},{ }^{7,8}$ but the functional role of this phosphorylation remains unknown.

Combinations of TRAIL with chemotherapeutic agents, including oxaliplatin, have been reported to generate synergistic antitumor responses in several human tumor types. ${ }^{9,10}$ Oxaliplatin, a third-generation platinum agent and usual chemotherapy agent for colon cancer, is thought to trigger cell death mainly by inducing platinum-DNA adducts, and appears to block DNA replication more effectively than other platinum compounds such as cisplatin. ${ }^{11}$ However, scarce data are available regarding the signaling pathways activated by oxaliplatin. The molecular basis of the synergy between chemotherapeutic drugs and TRAIL remains elu-

\footnotetext{
Abbreviations used in this paper: DR, death receptor; EV, empty vector; $\mathrm{IC}_{50}$, median inhibitory concentration; JNK, c-Jun N-terminal kinase; PI, propidium iodide; siRNA, small interfering RNA; S62, serine 62; S62A, serine 62 alanine; S62D, serine 62 asparagine; TRAIL, tumor necrosis factor-related apoptosis inducing ligand; WT, wild-type.

(c) 2011 by the AGA Institute 0016-5085/ \$36.00 doi:10.1053/j.gastro.2011.04.055
} 
sive, complex, cell type-dependent, and depends on the specific drug, its concentration, and route of administration. By using short exposure time for oxaliplatin pretreatment and subsequent stimulation with TRAIL, we previously showed that oxaliplatin and TRAIL acted synergistically by inducing apoptosis in TRAIL-resistant cancer cell lines. ${ }^{12} \mathrm{We}$

AQ: 20 show here that oxaliplatin induces $\mathrm{Bcl}-\mathrm{xL}$ phosphorylation at the serine 62 (S62) residue in a JNK-dependent manner. Phosphorylation of $\mathrm{Bcl}-\mathrm{xL}$ in turn induces the release of free Bax, allowing the activation of the mitochondrial pathway and thus activation of the apoptotic program after TRAIL stimulation.

\section{Materials and Methods}

For details see the online Supplementary Material and Methods section.

\section{Cell Culture and Drug Treatment}

Human colon cancer cell lines V9P were a gift from Dr R. Hamelin (INSERM U762, France) and HT29 were AQ: 21 from American Type Culture Collection. A fresh solution of AQ: 22 oxaliplatin (Eloxatin, $5 \mathrm{mg} / \mathrm{mL}$; Sanofi Aventis) was added to adherent cells for 2 hours, removed, and replaced with fresh medium alone or with medium containing recombinant human TRAIL (Peprotech $50 \mu \mathrm{g} / \mathrm{mL}$; Figure 1).

\section{Chemicals and Antibodies}

JNK inhibitor (SP600125) was from Calbiochem. Annexin V-fluorescein isothiocyanate and propidium iodide (PI) were from AbCys SA, and Annexin V-antigenpresenting cell was provided by Becton-Dickinson. RIPA Lysis Buffer Kit was provided by Santa Cruz Biotechnology. Primary antibodies for the following proteins were from Cell Signaling Technology: caspase-8, caspase-9, caspase-3, Bid, cytochrome c, Cox IV, Mcl-1, Bcl-2, Bcl-xL, and phosphorylated JNK; from Epitomics for Bax and Bak proteins, from Santa Cruz Biotechnology for Bax 2D2 and S62 phosphorylated Bcl-xL, from BD Pharmingen for Bax $6 \mathrm{~A} 7$, and from Sigma for $\alpha$-tubulin.

\section{Annexin V Staining and Flow Cytometry}

Cells were stained with Annexin V and PI according to the manufacturer's instructions (AbCys SA), and analyzed with a FACScanto II flow cytometer (BD BectonDickinson). Apoptotic cell percentage corresponded to Annexin $\mathrm{V}(+) / \mathrm{PI}(-)$ cells.

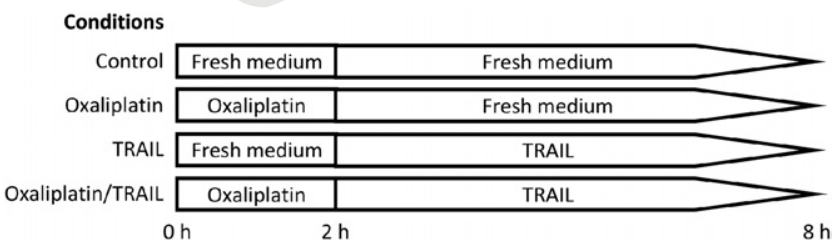

Figure 1. Treatment schedules. HT29 and V9P cancer cells were incubated for 2 hours with their respective $I C_{500 x a l i p l a t i n}$ and then with fresh medium (oxaliplatin condition) or TRAIL (oxaliplatin/TRAIL condition) for 6 hours. For TRAIL condition, cells were incubated with fresh medium for 2 hours then treated with TRAIL for 6 hours.

\section{Western Blot Analysis}

For immunoblotting, whole-cell extracts were prepared using RIPA buffer according to the manufacturer's instructions (Santa Cruz Biotechnology). Proteins were separated by sodium dodecyl sulfate-polyacrylamide gel electrophoresis, and transferred to a polyvinylidene difluoride membrane (Bio-Rad) by electroblotting. The antigen-antibody complexes were visualized using a chemiluminescence method (Covalab). Quantification was performed using a Bio-Rad imaging system.

\section{Cell Fractionation}

Mitochondrial and cytosolic fractions were prepared according to the manufacturer's instructions (Pierce Biotechnology). Equal amounts of proteins were subjected to electrophoresis and immunoblot analysis as described earlier.

\section{Phosphatase Treatment}

After cell lysis, lysates were clarified by centrifugation $\left(14,000 \mathrm{rpm}, 15\right.$ minutes at $\left.4^{\circ} \mathrm{C}\right)$, and divided into 2 equal aliquots. One aliquot was treated with 10 units of Calf Alkaline Phosphatase (Roche Diagnostics) and the other aliquot was mock-treated.

\section{Small Interfering RNA Transfection}

Small interfering RNA (siRNA) pool consisting of 4 siRNAs specific for each protein (ON-TARGET plus smart pool siRNAs; Dharmacon RNAi Technologies) were used to knock down caspase-8 (L-003466-00), caspase-3 (L-00430700), caspase-9 (L-003309-00), Bax (L-003308-01), Bak (L003305-00), and Bcl-xL (L-003454-00). For JNK silencing we used SignalSilence SAPK/JNK siRNA kit (Cell Signaling Technology), which provided 2 specific siRNAs for JNK. Control cells were transfected with a nontargeting siRNA (D-001206-13-05; Dharmacon). siRNAs were transfected at a final concentration of $100 \mathrm{nmol} / \mathrm{L}$ for 72 hours with DharmaFECT 4 following the manufacturer's protocols.

\section{Construction of the Bcl-xL Phosphorylation Mutant}

Substitution of S62 to asparagine (S62D) or alanine (S62A) into the pMIGR-BclXL-GFP retroviral plasmid was performed by polymerase chain reaction using the following specific oligonucleotides (Eurogentec): S62D sense: GGC-ACCTGG-CAG-ACG-ACC-CCG-CGG-TGA-ATG; S62D antisense: CAT-TCA-CCG-CGG-GGT-CGT-CTG-CCA-GGT-GCC; S62A sense: GCA-CCT-GGC-AGA-CGC-CCC-CGC-GGT-GAA-T; S62A antisense: ATT-CAC-CGC-GGG-GGC-GTC-TGC-CAGGTG-C. Mutations in the plasmids were checked by DNA sequencing (Beckman Coulter Genomics).

\section{Retrovirus Production and Cell Transduction}

Generation of retroviruses has been described previously. ${ }^{13}$ HT29 cells were transduced for 16 hours with 
$116 \mathrm{AQ}: 34$ viral supernatants containing polybrene $(8 \mathrm{mg} / \mathrm{mL})$, 117 washed in phosphate-buffered saline, and cultured in 118 complete medium. After transduction, GFP-positive cells 119 AQ: 35 were sorted using BD FACS vantage cell sorter.

\section{Immunoprecipitation}

Briefly, cells were lysed in CHAPS lysis buffer (150 $\mathrm{mmol} / \mathrm{L}$ sodium chloride, $10 \mathrm{mmol} / \mathrm{L}$ HEPES, $\mathrm{pH} 7.4$, and $1.0 \%$ Chaps) with freshly added proteases and phosphatase inhibitors (Santa Cruz Biotechnology) and immunoprecipitated with ExactaCruz product (Santa Cruz Biotechnology), thereby bypassing any signal caused by immunoglobulin $\mathrm{G}$ heavy and light chains of the IP antibody and following the manufacturer's guidelines.

\section{Statistical Analysis}

All data are summarized as mean \pm standard error of the mean of at least 3 separate experiments. The Student $t$ test was used to compare experimental with control groups. A $P$ value of less than .05 was considered statistically significant.
A

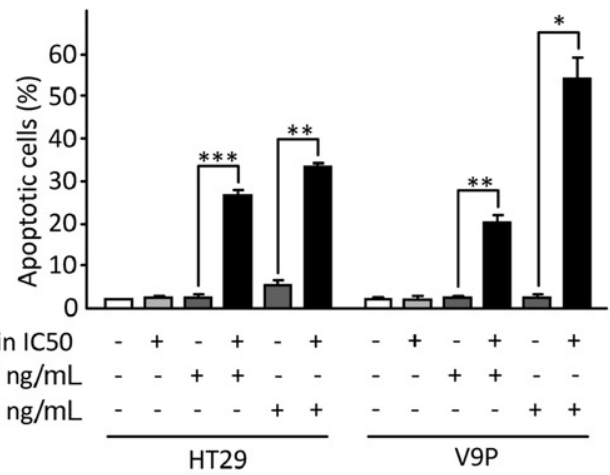
comparing caspase- 8 and caspase- 3 siRNAs with control siRNA.

\section{Results \\ Oxaliplatin Sensitizes HT29 and V9P Colon Cancer Cells to TRAIL-Induced Apoptosis}

HT29 and V9P colon cancer cells were pretreated with their median inhibitory concentration of oxaliplatin $\left(\mathrm{IC}_{500 x a l i p l a t i n}\right)(219.05 \mu \mathrm{mol} / \mathrm{L}$ and $19.19 \mu \mathrm{mol} / \mathrm{L}$, respectively) for 2 hours, then treated with 2 nonapoptotic doses of TRAIL ( 5 and $10 \mathrm{ng} / \mathrm{mL}$ ) for 6 hours. HT29 and V9P cells were both highly resistant to oxaliplatin and TRAIL-induced apoptosis as single treatments (Figure 2A). By contrast, the oxaliplatin/TRAIL combination significantly induced apoptosis in HT29 and V9P cells. Interestingly, when treating cells with TRAIL before oxaliplatin, the percentage of apoptotic cells did not increase significantly (Supplementary Figure 1), indicating that oxaliplatin pretreatment potentiated TRAIL-induced apoptosis. Western blot analysis revealed that the oxaliplatin/TRAIL combination greatly enhanced caspase-8 and caspase- 3 activation (Figure 2B). The increased caspase-8 activity after combined treatment was associated with cleavage of its substrate Bid, as indicated by a decreased intensity of the native 22-kilodalton form (Sup-
B

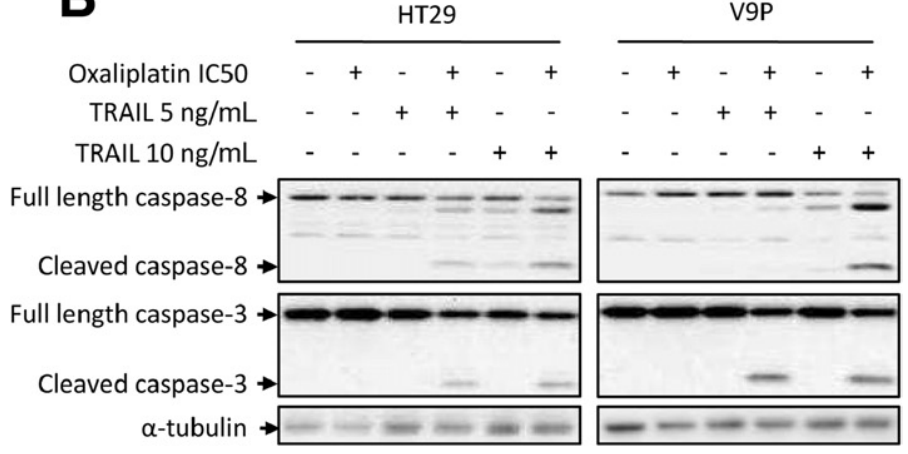

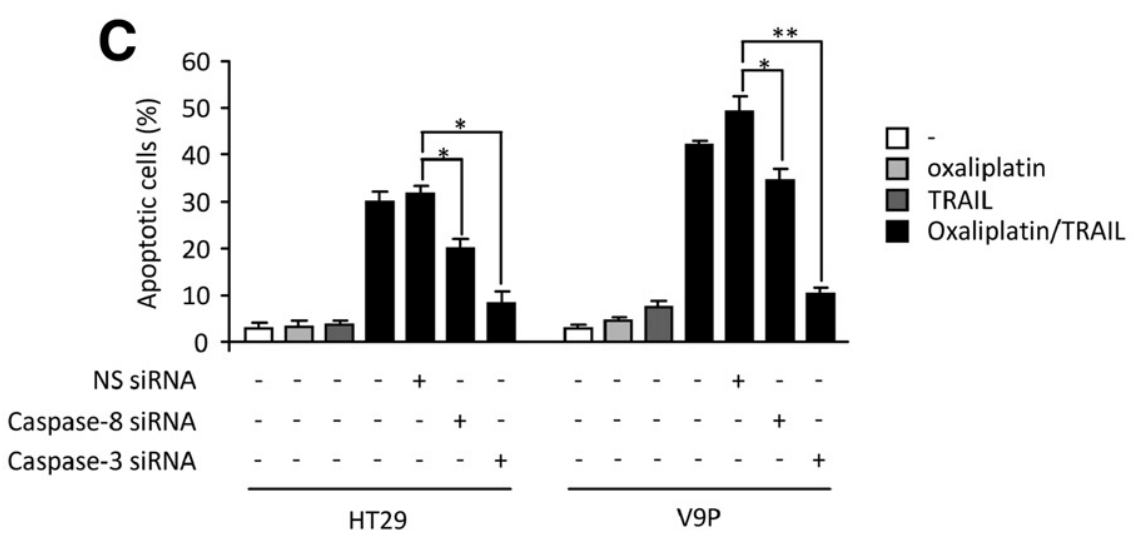

Figure 2. Oxaliplatin sensitizes colon cancer cells to TRAIL-induced apoptosis. HT29 and V9P cells were treated with oxaliplatin at IC 50 doses (219.05 $\mu \mathrm{mol} / \mathrm{L}$ for HT29 and $19.17 \mu \mathrm{mol} / \mathrm{L}$ for V9P cells) for 2 hours and then with TRAIL ( 5 or $10 \mathrm{ng} / \mathrm{mL}$ ) for 6 hours. (A) Data reflect the mean \pm standard error of the mean $(\mathrm{n}=3) .{ }^{*} P<.05 ;{ }^{* \star} P<.01 ;{ }^{* *} P<.001$ comparing oxaliplatin/TRAlL combination with TRAlL alone. (B) After treatments, cell lysates were used for Western blot analysis of caspase- 8 and caspase- 3 activation using specific antibodies. $\alpha$-tubulin expression was used as control for protein loading. Similar results were obtained in 3 independently performed experiments. (C) HT29 and V9P cells were transfected with caspase-8 and caspase-3 or control siRNAs (100 nmol/L) for 72 hours and then treated with oxaliplatin and TRAIL as described earlier. Apoptotic cell percentage represent Annexin $\mathrm{V}(+) / \mathrm{PI}(-)$ cells. Data reflect the mean \pm standard error of the mean $(n=3) .{ }^{\star} P<.05 ;{ }^{\star \star} P<.01$ 

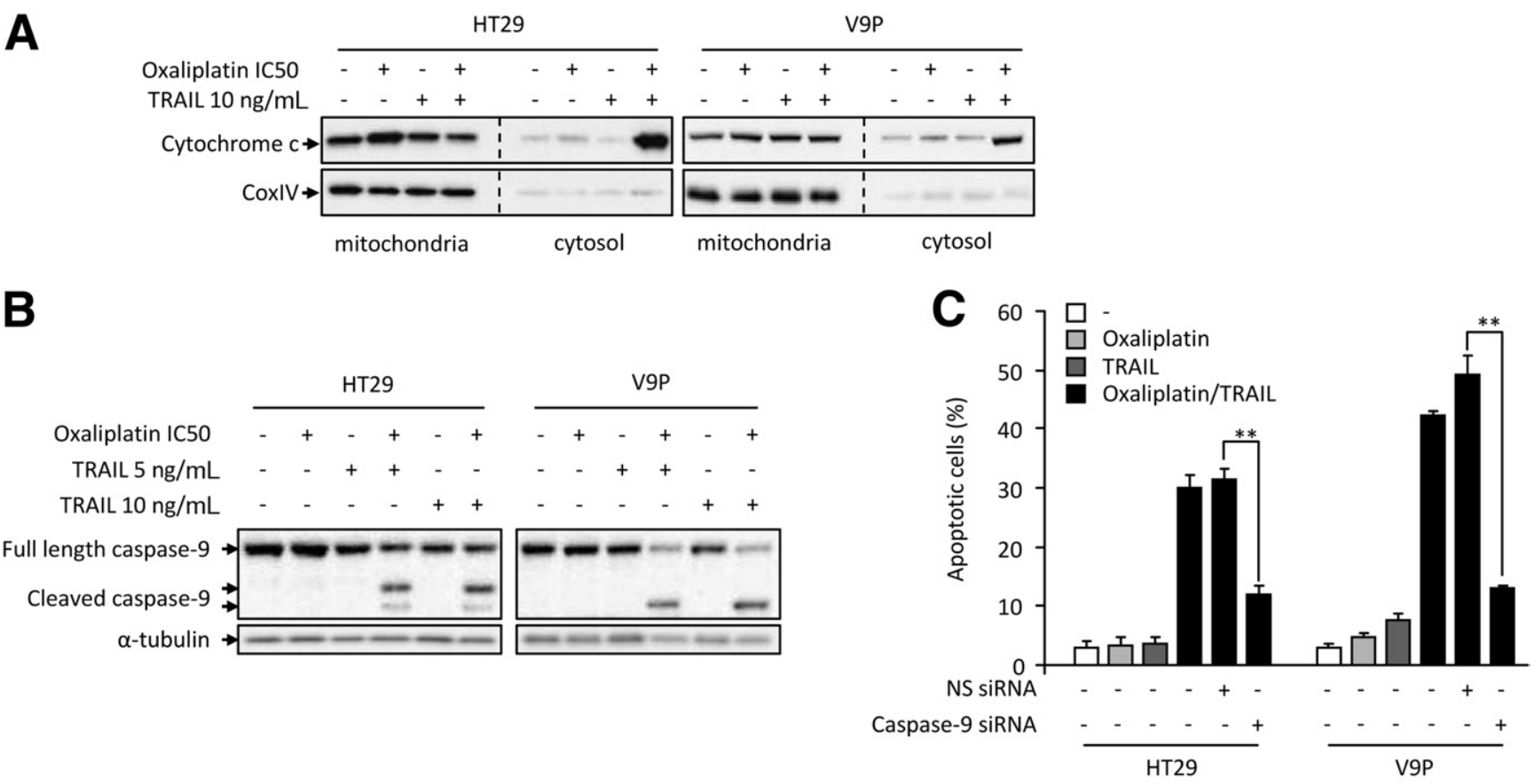

D

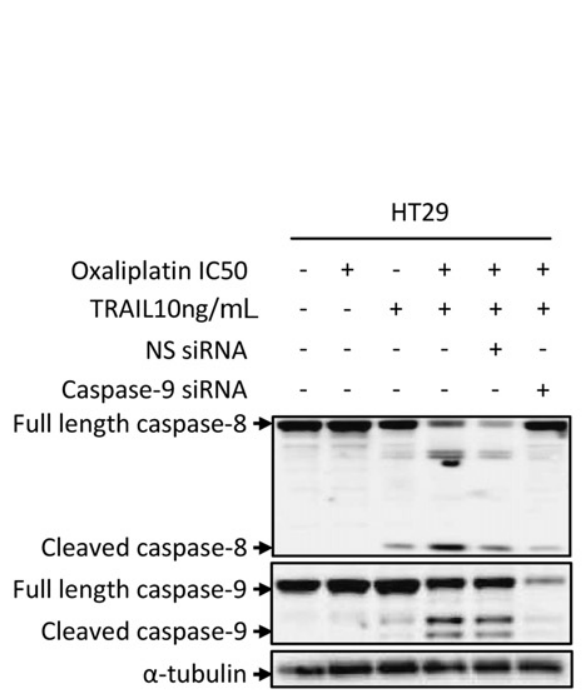
nontargeting siRNA.

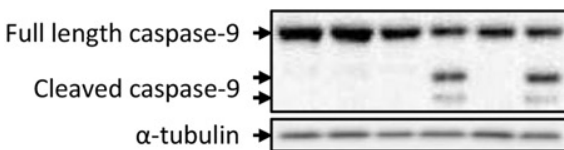

Figure 3. Mitochondria events are essential for oxaliplatin/TRAIL-induced apoptosis. ( $A$ and $B$ ) HT29 and V9P cells were treated with oxaliplatin $\left(\mathrm{IC}_{50}, 2 \mathrm{~h}\right)$, then TRAIL $(10 \mathrm{ng} / \mathrm{mL}, 2 \mathrm{~h})$, and after that Western blot analysis was performed for $(A)$ cytochrome $\mathrm{c}$ release and $(B)$ caspase- 9 activation. Fraction purity and protein loading were assessed by Cox IV and $\alpha$-tubulin blotting, respectively. HT29 and V9P cells were transfected with siRNA-mediating silencing of $(C$ and $D)$ caspase- 9 or $(E)$ Bax and Bak or nontargeting siRNAs (100 nmol/L) for 72 hours, and then treated with oxaliplatin $\left(\mathrm{IC}_{50}, 2 \mathrm{~h}\right)$ then TRAIL $(10 \mathrm{ng} / \mathrm{mL}, 6 \mathrm{~h})$. After treatments, $(C$ and $E)$ apoptotic cell percentage corresponding to Annexin $\mathrm{V}(+) / \mathrm{PI}(-)$ cells was measured by flow cytometry analysis and $(D)$ caspase-8 and caspase- 9 cleavage was assessed by Western blot analysis. Data reflect mean \pm standard error of the mean $(\mathrm{n}=3)$. ${ }^{*} P<.05 ;{ }^{*} P<.01$ comparing specific targeting siRNAs with

plementary Figure 2). Interestingly, caspase-8 silencing only slightly decreased the percentage of oxaliplatin/TRAIL-induced apoptotic cells in both cell lines, in contrast to caspase-3 knockdown (Figure 2C and Supplementary Figure $3 A$ and $B$ ). These results indicate that oxaliplatin pretreatment sensitizes resistant colon cancer cells to TRAIL in a caspase-3-dependent but caspase-8-independent manner.

\section{Oxaliplatin/TRAIL-Induced Apoptosis Is Controlled Predominantly by the Mitochondrial Pathway}

The oxaliplatin/TRAIL combination, but not single treatments, promoted cytochrome $\mathrm{c}$ release from the mitochondria into the cytosol (Figure 3A). Accordingly, Figure $3 B$ shows that only combined treatments led to caspase- 9 activation. Interestingly, inhibiting caspase-9 expression impaired the oxaliplatin/TRAIL-induced apoptosis in both cell lines (Figure 3C and Supplementary Figure 3C). Moreover, F3 caspase-9 silencing significantly reduced oxaliplatin/TRAILinduced caspase- 8 processing (Figure $3 D$ ). This result indicates that caspase- 8 activation occurs downstream of caspase-9. In addition, Bax silencing in HT29 cells, and Bax and Bak silencing in V9P cells, significantly reduced oxaliplatin/TRAIL-induced apoptosis (Figure $3 E$ and Supplementary Figure $3 D$ and $E$ ). Collectively, these results highlight the central role of the mitochondrial apoptotic pathway in oxaliplatin/TRAIL-induced apoptosis. 
A

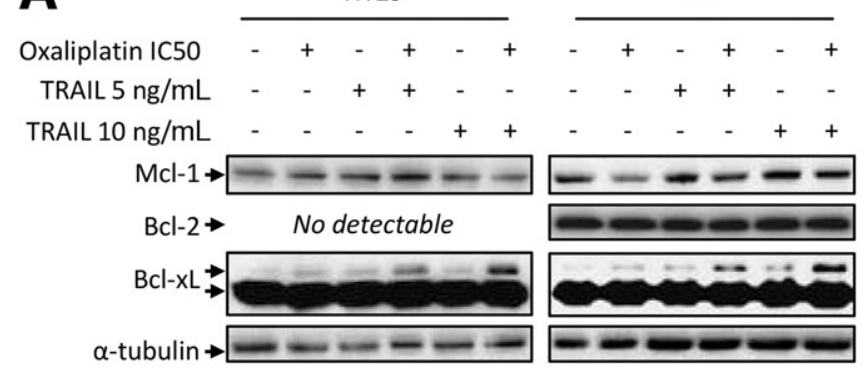

B
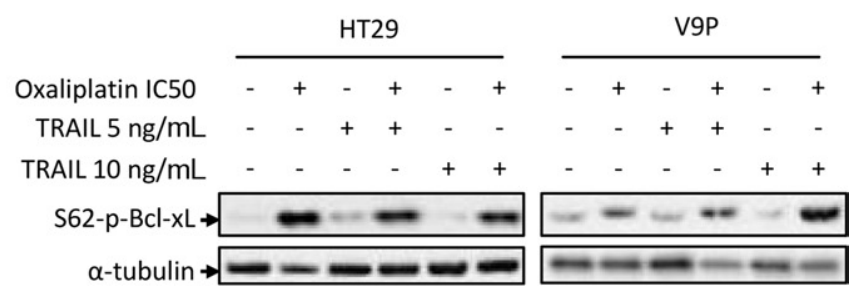

232

233

234

235

236

237

238

239

240

241

242

243

244

245

246

247

248

249

250

251

252

253

254

255

256

257

258

lation status of Bcl-xL were assessed by Western blot after oxaliplatin (I $\mathrm{C}_{50}, 2 \mathrm{~h}$ ) and then TRAlL $(10 \mathrm{ng} / \mathrm{mL}, 6 \mathrm{~h})$ treatments in HT29 and V9P cells $\alpha$-tubulin was used as a loading control. Similar results were obtained in 3 independent experiments. (C) HT29 and V9P cells were transfected with $100 \mathrm{nmol} / \mathrm{L}$ of Bcl-xL siRNA or nontargeting siRNA (NS siRNA). Seventy-two hours after transfection, cells were treated with oxaliplatin and then TRAIL as described earlier. Apoptotic cell percentage represent Annexin $\mathrm{V}(+) / \mathrm{PI}(-)$ cells. Data show the mean \pm standard error of the mean $(\mathrm{n}=$ 3). ${ }^{\star \star} P<.01 ;{ }^{* \star} P<.001$ comparing nontargeting siRNA with Bcl-xL siRNAs.

\section{Oxaliplatin Induces Bcl-xL Phosphorylation}

F4

Figure $4 A$ shows that the total amounts of antiapoptotic members of the Bcl-2 family were unchanged after exposure to oxaliplatin and/or TRAIL. However, a slower migrating Bcl-xL band after incubation of cells with the oxaliplatin/TRAIL combination appeared in both cell lines. In vitro phosphatase treatment of protein extracts obtained from HT29 cells completely abolished the slow migrating band, indicating that this post-translational modification could correspond to a phosphorylated form of Bcl-xL (Supplementary Figure $4 A$ ). Indeed, the use of a specific antibody recognizing the S62 phosphorylated form of Bcl-xL indicated that oxaliplatin induced the phosphorylation of Bcl-xL at S62 in both cell lines (Figure 4B). Oxaliplatin-induced Bcl-xL phosphorylation was maintained after TRAIL treatment (Figure 4B). Moreover, Bcl-xL siRNA restored the sensitivity of HT29 and V9P cells to TRAIL-induced apoptosis (Figure $4 C$ and Supplementary Figure $3 F$ ). Of note, the sensitizing effect of $\mathrm{Bcl}-\mathrm{xL}$ silencing was comparable with that obtained after oxaliplatin pretreatment (Figure 4C). This finding suggests that oxaliplatin-induced $\mathrm{Bcl}-\mathrm{xL}$ phosphorylation may decrease Bcl-xL anti-apoptotic activity, thus promoting TRAILinduced apoptosis.

\section{Oxaliplatin-Induced Bcl-xL Phosphorylation and Sensitization to TRAIL Require JNK Activation}

Phosphorylation of Bcl-xL has been reported to be mediated by several kinases, including JNK, in response to chemotherapeutic agents. $8,14,15$ Although TRAIL alone had no significant effect, oxaliplatin induced a rapid and prolonged JNK phosphorylation, the activation of which appeared to be strengthened by the combined treatment associating TRAIL (Figure 5A). As shown in Figure 5B, SP600125 (a specific JNK inhibitor) significantly reduced oxaliplatin/TRAIL-induced apoptosis in both cell lines. Moreover, JNK silencing significantly reduced apoptosis level in both cell lines (Figure 5C), indicating that the JNK pathway was crucial for oxaliplatin/TRAIL-induced apoptosis. We hypothesized that JNK may mediate oxaliplatin/TRAIL-induced apoptosis by targeting Bcl-xL. If so, the observed inhibitory effect of SP600125 on oxaliplatin/ TRAIL-induced apoptosis should not be observed in cells with reduced expression of Bcl-xL. Indeed, SP600125 treatment failed to diminish oxaliplatin/TRAIL-induced apoptosis in HT29 cells after Bcl-xL silencing (Figure 5D), suggesting that $\mathrm{Bcl}-\mathrm{xL}$ is one specific target for JNK. As shown in Figure 5E, pretreatment with SP600125 highly reduced the level of Bcl-xL phosphorylation in HT29 cells 
A
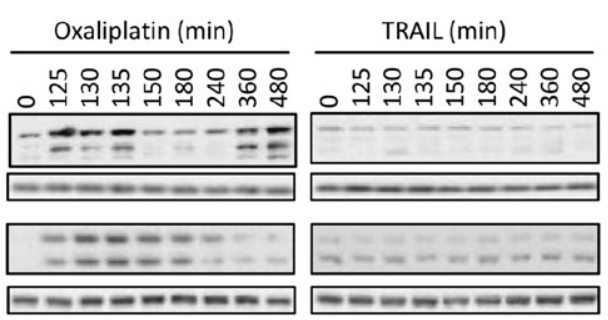
Oxaliplatin/TRAIL ( $\mathrm{min})$
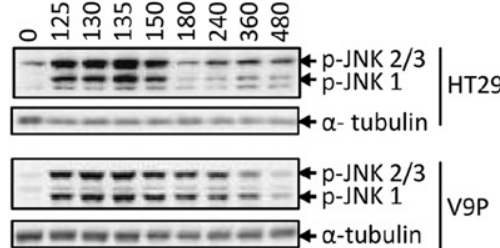
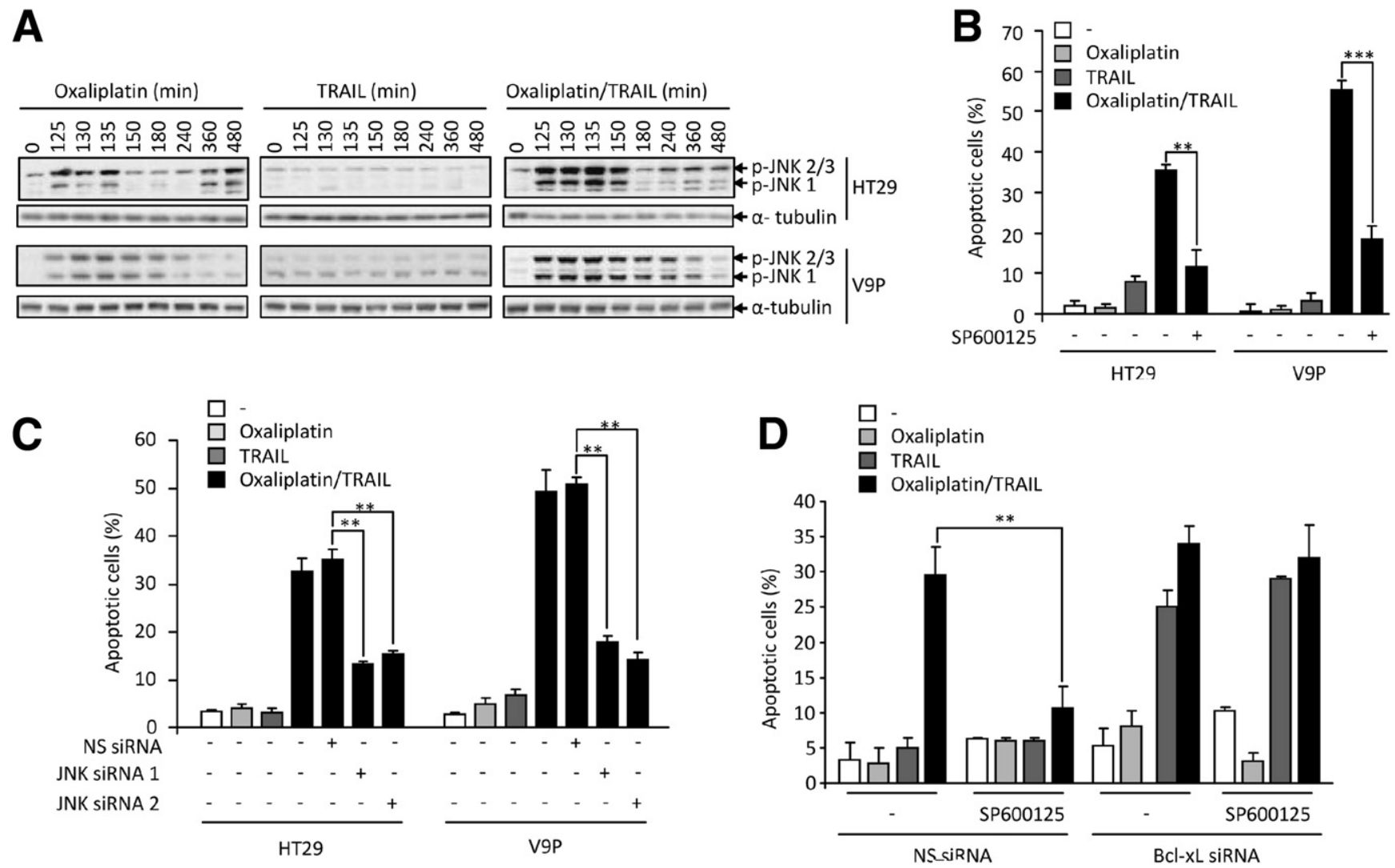

E
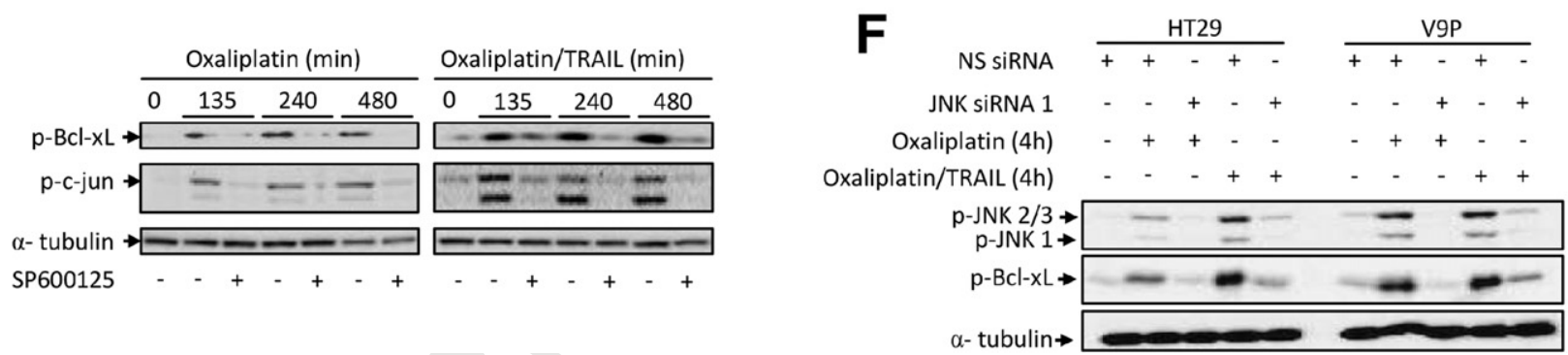

Figure 5. Oxaliplatin/TRAIL-induced apoptosis and Bcl-xL phosphorylation are JNK-dependent. (A) Phosphorylation status of JNK was analyzed by Western blot after oxaliplatin $\left(I_{50}\right)$ and TRAIL $(10 \mathrm{ng} / \mathrm{mL}$ ) treatments for the indicated time point. (B and C) HT29 and V9P cells were $(B)$ incubated for 30 minutes in the absence or presence of JNK inhibitor (SP600125, $20 \mu \mathrm{mol} / \mathrm{L}$ ) or (C) transfected with JNK siRNA or control siRNA (NS siRNA) for 72 hours and then treated with oxaliplatin $\left(I_{50}, 2 \mathrm{~h}\right)$ and then TRAIL $(10 \mathrm{ng} / \mathrm{mL}, 6 \mathrm{~h})$. Data show means \pm standard error of the mean $(n=3)$. ** $P<$ $.01 ;{ }^{* \star *} P<.001$ comparing treatments $(B)$ with and without SP600125 or (C) nontargeting siRNA with JNK target-specific siRNA. (D) HT29 cells were transfected with $100 \mathrm{nmol} / \mathrm{L}$ of Bcl-xL siRNA or control siRNA (NS siRNA). Seventy-two hours after transfection, cells were pretreated or not with SP600125 (20 $\mu \mathrm{mol} / \mathrm{L}, 30 \mathrm{~min})$ and then treated with oxaliplatin $\left(I \mathrm{I}_{50}, 2 \mathrm{~h}\right)$ and then TRAlL $(10 \mathrm{ng} / \mathrm{mL}, 6 \mathrm{~h})$. Apoptotic cell percentage represents Annexin $\mathrm{V}(+) / \mathrm{PI}(-)$ cells. Data show means \pm standard error of the mean $(\mathrm{n}=3) .{ }^{*} P<.01$ comparing treatments with and without SP600125. $(E)$ HT29 cells were pretreated or not with SP600125 (20 $\mu \mathrm{mol} / \mathrm{L}, 30 \mathrm{~min})$ and then treated with oxaliplatin or oxaliplatin/TRAlL combination for the indicated time points. Bcl-XL phosphorylation was determined by Western blot analysis. SP600125 efficiency was controlled by analyzing p-c-Jun expression. (F) HT29 and V9P cells were transfected with $100 \mathrm{nmol} / \mathrm{L}$ of JNK siRNA or nontargeting siRNA (NS siRNA) for 72 hours. Cells then were treated with oxaliplatin or oxaliplatin/TRAIL combination for 4 hours. Bcl-xL phosphorylation was determined by Western blot analysis. $\alpha$-tubulin served as loading control. Similar results were obtained in 3 independent experiments.

upon oxaliplatin stimulation. In addition, JNK silencing reduced the amount of S62-phosphorylated Bcl-xL after oxaliplatin and oxaliplatin/TRAIL treatment in both cell lines (Figure $5 F$ ). These data provide strong experimental evidence that oxaliplatin-induced Bcl-xL phosphorylation requires JNK activation.

\section{Bcl-xL Phosphorylation Is Responsible for Decreased Anti-Apoptotic Activity}

To evaluate the role of $\mathrm{Bcl}-\mathrm{xL}$ phosphorylation on its own anti-apoptotic activity, we established HT29-derived cell lines stably overexpressing wild-type Bcl-xL (HT29-BclxL.WT), Ser62/Asp phospho-mimic Bcl-xL mutant (HT29Bcl-xL.S62D), Ser62/Ala phospho-defective Bcl-xL mutant (HT29-Bcl-xL.S62A), or the corresponding empty vector (HT29-EV). WT and S62D Bcl-xL proteins were overexpressed to a similar extent and $\mathrm{S} 62 \mathrm{~A} \mathrm{Bcl-xL}$ protein to a lower level ( 40\% less than WT and S62D Bcl-xL) (Figure $6 A$ ). Only Bcl-xL.S62D was recognized by the phospho-spe- $\mathrm{F} 6$ cific anti-Bcl-xL antibody (Figure 6A). As expected, overexpression of the WT Bcl-xL completely prevented oxaliplatin/ 


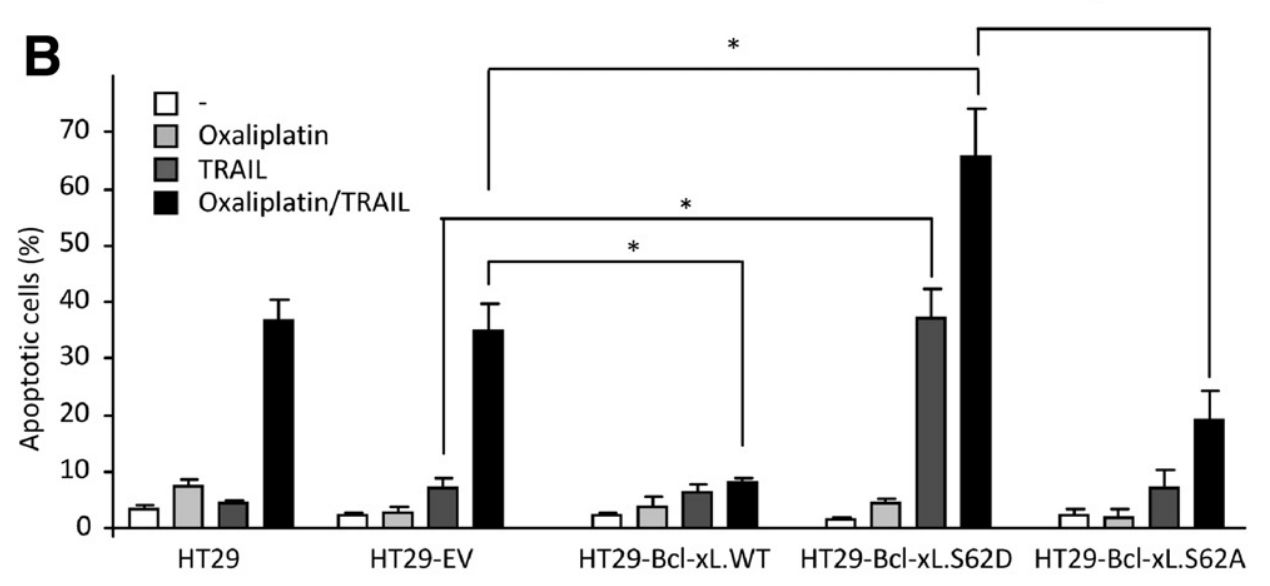

C

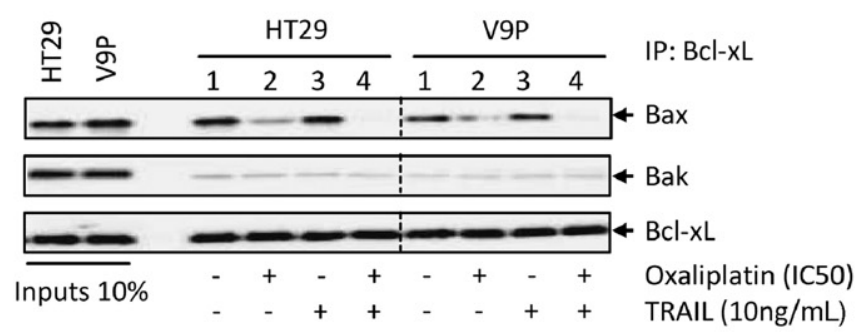

D

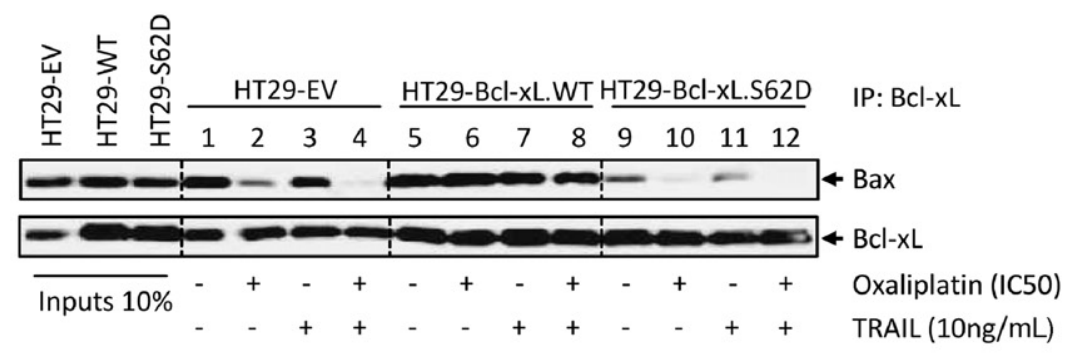

E

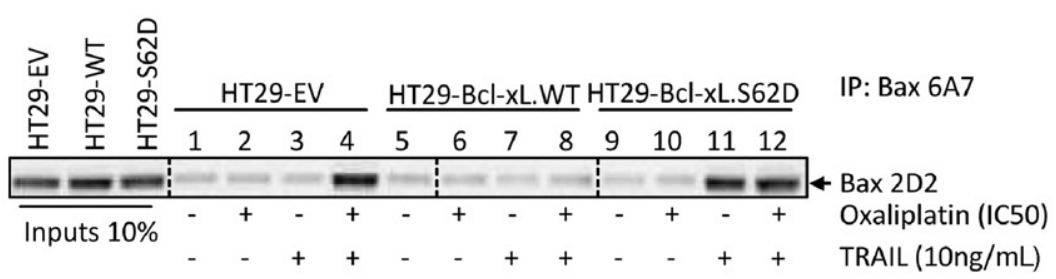

F

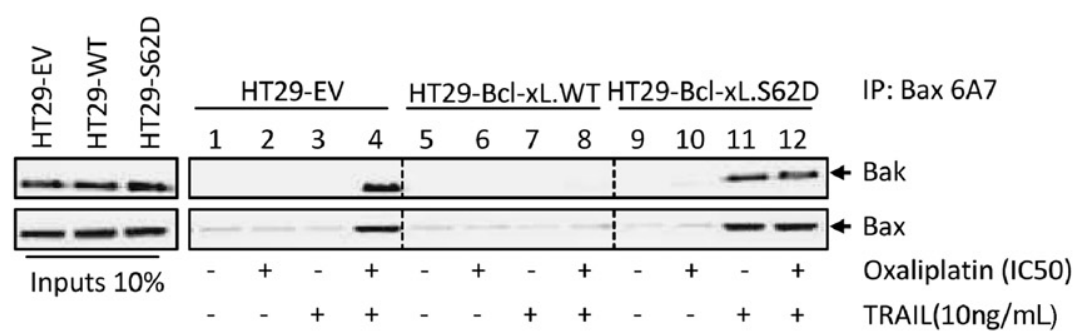

Figure 6. Oxaliplatin-induced Bcl-xL phosphorylation decreased its anti-apoptotic activity. HT29 cells were transfected with plasmid DNA carrying a GFP vector (HT29-EV) or encoding wild-type Bcl-xL (HT29-Bcl-xL.WT), phospho-mimic Bcl-xL (HT29-Bcl-xL.S62D), or phospho-defective Bcl-xL (HT29-Bcl-XL.S62A). (A) Extracts from untransfected HT29, or stably transfected HT29-EV, HT29-Bcl-XL.WT, HT29-Bcl-xL.S62D, and HT29-BclxL.S62A were made and subjected to immunoblotting for Bcl-xL and phospho-Bcl-xL. (B) HT29, HT29-EV, HT29-Bcl-xL.WT, HT29-Bcl-xL.S62D, and HT29-Bcl-XL.S62A cells were subjected to oxaliplatin $\left(\mathrm{IC}_{50}, 2 \mathrm{~h}\right)$ and then TRAIL $(10 \mathrm{ng} / \mathrm{mL}, 6 \mathrm{~h})$ treatments. Apoptotic cell percentages represent Annexin $\mathrm{V}(+) / \mathrm{PI}(-)$ cells. Results are means \pm standard error of the mean $(n=3)$. ${ }^{*} P<.05$. (C) HT29 and V9P cells or (D) HT29-EV, HT29-Bcl-xL.WT, and HT29-Bcl-XL.S62D cells were treated with oxaliplatin $\left(\mathrm{IC}_{50}, 2 \mathrm{~h}\right)$ and then TRAIL $(10 \mathrm{ng} / \mathrm{mL}, 4 \mathrm{~h})$ and subjected to immunoprecipitation with anti-Bcl-XL monoclonal antibody. Samples were analyzed by immunoblotting for Bax, Bcl-xL, and Bak. Similar results were obtained in 3 independently performed experiments. ( $E$ and F) HT29-EV, HT29-Bcl-XL.WT, and HT29-Bcl-xL.S62D cells were treated with oxaliplatin (IC $50,2 \mathrm{~h}$ ) and then TRAIL (10 ng/mL, $4 \mathrm{~h}$ ) and subjected to immunoprecipitation with anti-Bax 6A7 monoclonal antibody followed by immunoblot analysis with ( $E$ ) anti-Bax 2D2 antibody and (F) anti-Bak antibody. 
TRAIL-induced apoptosis (Figure 6B), confirming that it largely relies on the mitochondrial pathway. Interestingly, ectopic expression of the phospho-mimic Bcl-xL S62D enhanced apoptosis induced by TRAIL alone and in combination with oxaliplatin, whereas HT29-Bcl-xL.S62A cells were clearly more resistant to oxaliplatin/TRAIL combination. Because Bcl-xL has been shown to inhibit apoptosis by interacting with $\mathrm{Bax}^{16}$ and/or Bak, ${ }^{17}$ we next tested whether combined treatments, through Bcl-xL phosphorylation, may alter their interactions with Bcl-xL. An interaction between Bcl-xL and Bax was detected in control and TRAIL-treated cells (Figure 6C, lanes 1 and 3). This interaction was reduced significantly after oxaliplatin treatment, independently of TRAIL stimulation (lanes 2 and 4). On the other hand, no significant interaction was detected between Bcl-xL and Bak in both cell lines (Figure 6C). Moreover, phospho-mimic Bcl-xL (S62D) showed a weaker interaction with Bax in control cells, as compared with the WT Bcl-xL (Figure 6D, lanes 5 and 9). Furthermore, although Bcl-xL/Bax heterodimers were maintained upon treatment in HT29-BclxL.WT (Figure 6D, lanes 6-8), this interaction was impaired in the presence of oxaliplatin in HT29-Bcl-xL.S62D (Figure $6 D$, lanes 10 and 12). These observations were confirmed in reciprocal anti-Bax immunoprecipitation (Supplementary Figure 5). The lack of interaction between Bcl-xL and Bak was confirmed in HT29.EV, HT29.WT, and HT29-BclxL.S62D cells (Supplementary Figure 6), suggesting that the role of Bak regarding oxaliplatin/TRAIL-induced apoptosis is not related to $\mathrm{Bcl}-\mathrm{xL} / \mathrm{Bak}$ interaction.

We next sought to determine the activation status of Bax released from Bcl-xL/Bax heterodimers by immunoprecipitation experiments with the anti-Bax 6A7 antibody, which specifically recognizes active Bax. ${ }^{18}$ Bax was activated exclusively with the combined treatment in HT29.EV cells (Figure $6 E$, lane 4), but not in HT29-Bcl-xL.WT (lane 8). In agreement with the hypothesis that $\mathrm{Bcl}-\mathrm{xL}$ phosphorylation prevents Bax sequestration, Bax activation was detected after both TRAIL and oxaliplatin/TRAIL treatments in HT29-BclxL.S62D cells (Figure 6E, lanes 11 and 12). Moreover, as shown by co-immunoprecipitation, Bak only interacted with active Bax in HT29-EV cells treated with the oxaliplatin/ TRAIL combination (Figure 6F, lane 4) or HT29-BclxL.S62D cells treated with TRAIL alone irrespective of oxaliplatin pretreatment (Figure 6F, lanes 11 and 12). Bax/Bak interaction was dependent entirely on Bax activation because Bak was immunoprecipitated only in cell extracts corresponding to active Bax (Supplementary Figure 7, lanes 4, 11, and 12). These results indicate that oxaliplatin primes mitochondrial activation by inhibiting Bcl-xL-induced Bax sequestration, thus allowing Bax/Bak interaction upon apoptosis engagement.

\section{Discussion}

The molecular basis of resistance to TRAIL-induced cytotoxicity is complex and multifactorial. ${ }^{6,19}$ However, this resistance can be overcome by combining TRAIL with cytotoxic agents. ${ }^{9,10}$ Accordingly, we previously showed that oxaliplatin enhances TRAIL cytotoxicity in a large panel of colon cancer cell lines. ${ }^{12}$

The sensitizing effects of chemotherapeutic drugs to TRAIL-induced apoptosis have been attributed to 3 main molecular events: (1) up-regulation of TRAIL death receptors DR4/DR5, ${ }^{20}$ (2) enhancement of death-inducing signaling complex formation/function, ${ }^{21}$ and/or (3) alteration of the expression level of pro-apoptotic/anti-apoptotic proteins. ${ }^{22}$ We previously reported that oxaliplatin had no effect on TRAIL DRs cell surface expression in both HT29 and V9P cells, ${ }^{12}$ arguing against the first possibility. The contribution of DR up-regulation remains a matter of debate. ${ }^{23}$ Despite functional expression of DR4/DR5 TRAIL receptors, ${ }^{19}$ a significant proportion of cultured malignant cells remain refractory to the cytotoxic effect of recombinant soluble TRAIL. In agreement with this observation, caspase- 9 silencing, but not caspase- 8 silencing, abrogated oxaliplatin/TRAIL-induced cell death, arguing against the possible involvement of membrane-related regulatory events including death-inducing signaling complex formation/function enhancement. On the contrary, oxaliplatin-induced sensitization to TRAIL required activation of the mitochondrial pathway, allowing a caspase-dependent feedback loop. These results are in agreement with data showing that caspase- 9 can act as a feedback loop by cleaving caspase- 8 to amplify the apoptotic process. ${ }^{24}$ Further supporting this conclusion is the demonstration that Bax and Bak inhibition, or Bcl-xL overexpression, abrogated oxaliplatin/TRAIL-induced cell death. These observations clearly indicate that HT29 and V9P cancer cells behave as type II cells in which DRinduced apoptosis is controlled mainly by anti-apoptotic Bcl-2 family proteins. ${ }^{6,25}$ Interestingly, although $\mathrm{Mcl}-1$, $\mathrm{Bcl}-2$, or Bcl-xL expression levels were unaffected by oxaliplatin, a partial Bcl-xL phosphorylation was induced in both cell lines. Our data show Bcl-xL phosphorylation in response to a DNA-damaging agent. This finding is in contrast with previous reports suggesting that $\mathrm{Bcl}-\mathrm{xL}$ phosphorylation is a specific consequence of antimitotic agents, ${ }^{7,14}$ explaining, in part, their ability to induce cellcycle arrest. $^{26}$ Interestingly, we previously showed that oxaliplatin treatment resulted in HT29 and V9P cell-cycle arrest. $^{27}$ This finding could explain why oxaliplatin can promote $\mathrm{Bcl}-\mathrm{xL}$ phosphorylation.

$\mathrm{Bcl}-\mathrm{xL}$ phosphorylation has been attributed to the activation of several kinases including JNK. ${ }^{8,26}$ On the one hand, Mucha et $\mathrm{al}^{28}$ observed that JNK inhibition sensitizes hepatocellular carcinoma cells to TRAIL, but other groups have shown that JNK activation sensitizes hepatocellular carcinoma and breast cancer cells to TRAIL-induced apoptosis. ${ }^{29,30}$ Our results would rather support the second conclusion because apoptosis induced by oxaliplatin/TRAIL combination was strongly suppressed by JNK inhibition or knockdown. Several studies have focused on the implication of JNK activation in apoptosis induced by the mitochondrial pathway. It has been reported that JNK was required for stress-induced release of cytochrome $\mathrm{c}$ from mitochondria into the cytosol. ${ }^{31}$ An- 


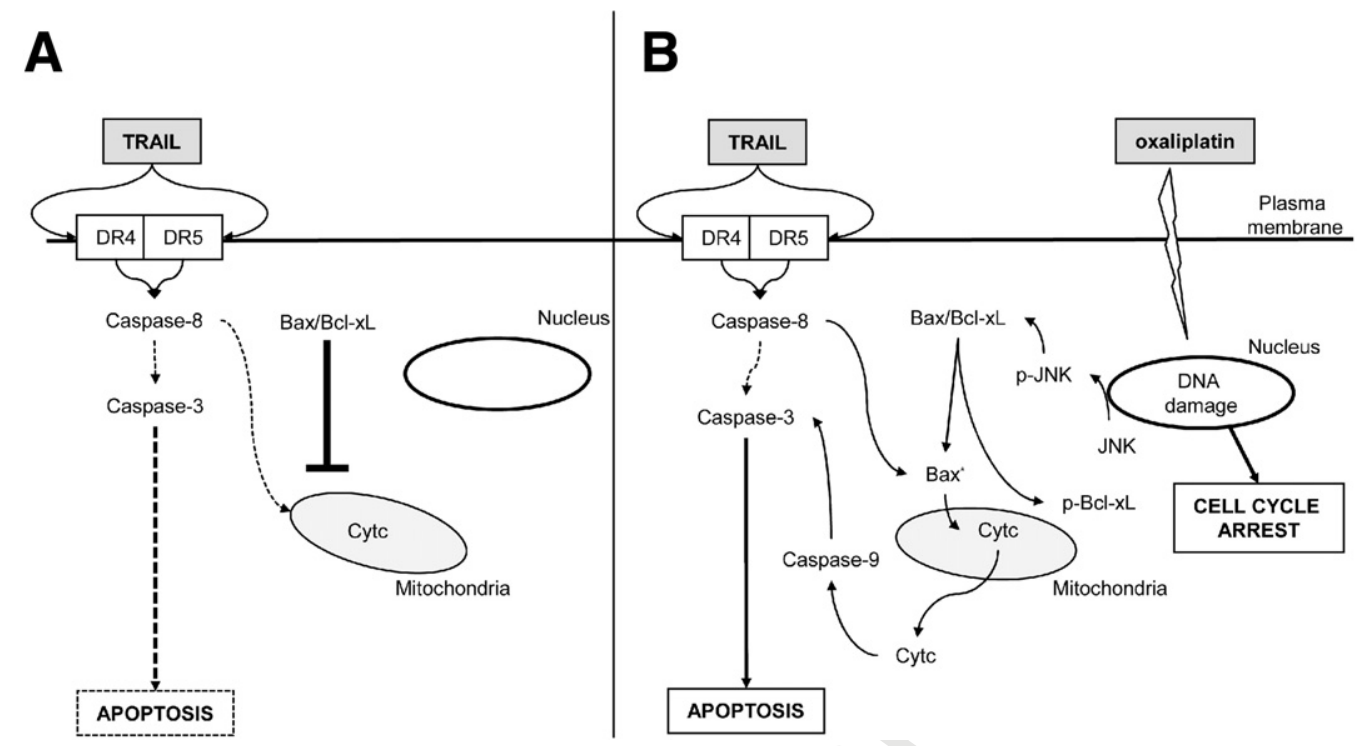

Figure 7. Proposed mechanism for oxaliplatin-sensitizing effect to TRAIL. (A) TRAIL alone fails to reach a critical threshold to induce apoptosis because of its incapacity to overcome mitochondrial blockage. If cells are pretreated with oxaliplatin, $(B)$ Bcl-xL is phosphorylated in a JNKdependent manner and Bax is released, driving mitochondrial signaling beyond a level compatible with cell death, causing cytochrome $\mathrm{c}$ release and caspase- 9 activation. Caspase- 9 on its turn activates caspase-8 through the feedback loop, leading to death-signaling amplification.

other study suggested that activated JNK might translocate to mitochondria and associate with Bcl-xL in response to cellular stress. ${ }^{32}$ It also was reported that activation of JNK signaled mitochondrial translocation of Bax and Bcl-2 phosphorylation, resulting in mitochondrial apoptotic cell death. ${ }^{33}$ In line with these findings, we show here that oxaliplatin-mediated Bcl-xL phosphorylation was dependent on JNK activation as shown by the use of JNK inhibitors or by JNK siRNA.

Overexpression of a S62 phospho-defective or phosphomimetic form of $\mathrm{Bcl}-\mathrm{xL}$ provided strong support to our findings that JNK-induced $\mathrm{Bcl}-\mathrm{xL}$ phosphorylation accounts for the restoration of the mitochondrial program and sensitivity to TRAIL-induced apoptosis, recapitulating the effect of oxaliplatin in these cells. It is worth mentioning that several reports already proposed the hypothesis that $\mathrm{Bcl}-\mathrm{xL}$ anti-apoptotic function may be more critically related to its phosphorylation status than to its expression level.7,34 Of note, it was surprising to observe that cells overexpressing phospho-defective $\mathrm{Bcl}-\mathrm{xL}$ were less resistant to oxaliplatin/TRAIL combination than those expressing the WT protein. This observation could be explained in part by the fact that phospho-defective Bcl-xL mutant was less overexpressed $(\sim 40 \%)$ than WT Bcl-xL.

$\mathrm{Bcl}-\mathrm{xL}$ protects cells from programmed cell death by dimerizing with and sequestering $\mathrm{Bax}^{16}$ and Bak. ${ }^{17}$ The finding that oxaliplatin-induced $\mathrm{Bcl}-\mathrm{xL}$ phosphorylation compromises its ability to interact with Bax, as shown by co-immunoprecipitation analysis, accounts on its own for the restoration of TRAIL sensitivity in these cells. Moreover, these experiments showed that the phospho-mimic Bcl-xL mutant was unable to bind Bax even at basal conditions. Of note, and as previously shown, ${ }^{27}$ despite its ability to induce Bcl-xL phosphorylation and Bax release, oxaliplatin alone was unable to induce apoptosis, indicating that additional events are required to engage the apoptotic program. Indeed, Bax translocation to mitochondria appears to be essential for Bax activation and apoptosis. ${ }^{18,35,36}$ Oxaliplatin was unable to induce Bax conformational changes on its own, probably explaining, at least in part, its inefficiency in inducing apoptosis. The fact that Bax conformational changes occur only when oxaliplatin and TRAIL are combined suggests that in addition to its release from $\mathrm{Bcl}-\mathrm{xL}$, Bax activation requires additional events related to TRAIL/DR signaling. This hypothesis is supported by the observation that TRAIL alone induces Bax activation in HT29-Bcl-xL.S62D cells because $\mathrm{Bax}$ is no more sequestered by $\mathrm{Bcl}-\mathrm{xL}$ because of its phosphorylation at the S62 site. Bax release from $\mathrm{Bcl}-\mathrm{xL}$ therefore may represent the first step leading to Bax insertion into the mitochondrial membrane. Bax conformational changes are required for mitochondrial membrane permeabilization. The molecular mechanisms for Bax activation are not completely known but the involvement of the BH3-only protein Bid or RASSF1A has been proposed to play a substantial role. ${ }^{18,36,37}$ Among these, Bid is probably the best-studied activator of Bax. In fact, Eskes et $\mathrm{al}^{36}$ showed that Bid was able to induce Bax conformational change leading to the exposure of its $\mathrm{N}$-terminal domain, allowing Bax integration in the outer mitochondrial membrane. In our experimental conditions, Bid is probably a good candidate because we have shown its cleavage upon TRAIL treatment. However, further experiments are needed to elucidate its involvement and we cannot exclude the possibility that other proteins, including RASSF1A, may take part in this process. 
Importantly, although Bcl-xL is unable to sequester Bak directly (as shown by our immunoprecipitation experiments), its anti-apoptotic activity respective to Bak itself may result from its ability to sequester Bax.

Taken together, our results unveil a novel molecular signaling mechanism explaining how a DNA-damaging agent, such as oxaliplatin, synergizes with TRAIL to restore apoptosis in resistant colon cancer cell lines (Figure

F7 7). Inactivating Bcl-xL represents a good opportunity to restore sensitivity to apoptosis. Given the fact that oxaliplatin is a commonly used chemotherapeutic drug for colon cancers, and that TRAIL currently is undergoing clinical testing, this drug combination has an excellent translational potential and should be considered for clinical development.

\section{Supplementary Material}

Note: To access the supplementary material accompanying this article visit the online version of Gastroenterology at www.gastrojournal.org and at doi:10.1053/ j.gastro.2011.04.055.

\section{References}

1. Merino D, Lalaoui N, Morizot A, et al. TRAIL in cancer therapy: present and future challenges. Expert Opin Ther Targets 2007;11: 1299-1314.

2. Almasan A, Ashkenazi A. Apo2L/TRAIL: apoptosis signaling, biology, and potential for cancer therapy. Cytokine Growth Factor Rev 2003;14:337-348.

3. Scaffidi C, Fulda S, Srinivasan A, et al. Two CD95 (APO-1/Fas) signaling pathways. EMBO J 1998;17:1675-1687.

4. Fulda S, Meyer E, Friesen C, et al. Cell type specific involvement of death receptor and mitochondrial pathways in drug-induced apoptosis. Oncogene 2001;20:1063-1075.

5. Chipuk JE, Moldoveanu T, Llambi F, et al. The BCL-2 family reunion. Mol Cell 2010;37:299-310.

6. Zhang L, Fang B. Mechanisms of resistance to TRAIL-induced apoptosis in cancer. Cancer Gene Ther 2005;12:228-237.

7. Upreti M, Galitovskaya EN, Chu R, et al. Identification of the major phosphorylation site in Bcl-xL induced by microtubule inhibitors and analysis of its functional significance. J Biol Chem 2008;283: 35517-35525.

8. Kharbanda S, Saxena S, Yoshida K, et al. Translocation of SAPK/ JNK to mitochondria and interaction with $\mathrm{Bcl}-\mathrm{x}(\mathrm{L})$ in response to DNA damage. J Biol Chem 2000;275:322-327.

9. Galligan L, Longley DB, McEwan M, et al. Chemotherapy and TRAIL-mediated colon cancer cell death: the roles of p53, TRAIL receptors, and c-FLIP. Mol Cancer Ther 2005;4:2026-2036.

10. Xu L, Qu X, Zhang $Y$, et al. Oxaliplatin enhances TRAIL-induced apoptosis in gastric cancer cells by CBL-regulated death receptor redistribution in lipid rafts. FEBS Lett 2009;583:943-948.

11. Raymond E, Faivre S, Chaney S, et al. Cellular and molecular pharmacology of oxaliplatin. Mol Cancer Ther 2002;1:227-235.

12. Toscano F, Fajoui ZE, Gay F, et al. P53-mediated upregulation of DcR1 impairs oxaliplatin/TRAIL-induced synergistic anti-tumour potential in colon cancer cells. Oncogene 2008;27:4161-4171.

13. Micheau O, Lens S, Gaide O, et al. NF-kappaB signals induce the expression of c-FLIP. Mol Cell Biol 2001;21:5299-5305.

14. Fan M, Goodwin M, Vu T, et al. Vinblastine-induced phosphorylation of $\mathrm{Bcl}-2$ and $\mathrm{Bcl}-\mathrm{xL}$ is mediated by JNK and occurs in parallel with inactivation of the Raf-1/MEK/ERK cascade. J Biol Chem 2000;275:29980-29985.

15. Jin HO, Seo SK, Woo SH, et al. A combination of sulindac and arsenic trioxide synergistically induces apoptosis in human lung cancer H1299 cells via c-Jun NH2-terminal kinase-dependent Bcl-xL phosphorylation. Lung Cancer 2008;61:317-327.

16. Wang $X$, Xing $D$, Liu $L$, et al. BimL directly neutralizes $B c l-x L$ to promote Bax activation during UV-induced apoptosis. FEBS Lett 2009;583:1873-1879.

17. van Delft MF, Huang DC. How the Bcl-2 family of proteins interact to regulate apoptosis. Cell Res 2006;16:203-213.

18. Wolter KG, Hsu YT, Smith CL, et al. Movement of Bax from the cytosol to mitochondria during apoptosis. J Cell Biol 1997;139: 1281-1292.

19. Shankar S, Srivastava RK. Enhancement of therapeutic potential of TRAIL by cancer chemotherapy and irradiation: mechanisms and clinical implications. Drug Resist Update 2004;7: $139-156$.

20. Kondo K, Yamasaki S, Sugie T, et al. Cisplatin-dependent upregulation of death receptors 4 and 5 augments induction of apoptosis by TNF-related apoptosis-inducing ligand against esophageal squamous cell carcinoma. Int J Cancer 2006;118: 230-242.

21. Lacour S, Micheau O, Hammann A, et al. Chemotherapy enhances TNF-related apoptosis-inducing ligand DISC assembly in HT29 human colon cancer cells. Oncogene 2003;22:1807-1816.

22. Kim JH, Ajaz M, Lokshin A, et al. Role of antiapoptotic proteins in tumor necrosis factor-related apoptosis-inducing ligand and cisplatin-augmented apoptosis. Clin Cancer Res 2003;9:31343141.

23. Kyritsis AP, Tachmazoglou F, Rao JS, et al. Bortezomib sensitizes human astrocytoma cells to tumor necrosis factor related apoptosis-inducing ligand induced apoptosis. Clin Cancer Res 2007; 13:6540-6541; author reply, 6541-6542.

24. Slee EA, Harte MT, Kluck RM, et al. Ordering the cytochrome c-initiated caspase cascade: hierarchical activation of caspases-2, -3, -6, $-7,-8$, and -10 in a caspase-9-dependent manner. J Cell Biol 1999; 144:281-292.

25. Schulze-Bergkamen H, Ehrenberg R, Hickmann L, et al. Bcl-x $(\mathrm{L})$ and myeloid cell leukaemia-1 contribute to apoptosis resistance of colorectal cancer cells. World J Gastroenterol 2008;14:3829_ 3840.

26. Terrano DT, Upreti M, Chambers TC. Cyclin-dependent kinase 1-mediated $\mathrm{Bcl}-\mathrm{xL} / \mathrm{Bcl}-2$ phosphorylation acts as a functional link coupling mitotic arrest and apoptosis. Mol Cell Biol 2010;30: 640-656.

27. Toscano F, Parmentier B, Fajoui ZE, et al. p53 dependent and independent sensitivity to oxaliplatin of colon cancer cells. Biochem Pharmacol 2007;74:392-406.

28. Mucha SR, Rizzani A, Gerbes AL, et al. JNK inhibition sensitises hepatocellular carcinoma cells but not normal hepatocytes to the TNF-related apoptosis-inducing ligand. Gut 2009;58:688698.

29. Wang C, Chen T, Zhang N, et al. Melittin, a major component of bee venom, sensitizes human hepatocellular carcinoma cells to tumor necrosis factor-related apoptosis-inducing ligand (TRAIL)induced apoptosis by activating CaMKII-TAK1-JNK/p38 and inhibiting IkappaBalpha kinase-NFkappaB. J Biol Chem 2009;284: 3804-3813.

30. Nakshatri H, Rice SE, Bhat-Nakshatri P. Antitumor agent parthenolide reverses resistance of breast cancer cells to tumor necrosis factor-related apoptosis-inducing ligand through sustained activation of c-Jun N-terminal kinase. Oncogene 2004;23:73307344.

31. Tournier C, Hess P, Yang DD, et al. Requirement of JNK for stress-induced activation of the cytochrome c-mediated death pathway. Science 2000;288:870-874.

32. Ito $\mathrm{Y}$, Mishra NC, Yoshida $\mathrm{K}$, et al. Mitochondrial targeting of JNK/SAPK in the phorbol ester response of myeloid leukemia cells. Cell Death Differ 2001;8:794-800.

33. Kang YH, Lee SJ. The role of p38 MAPK and JNK in arsenic trioxide-induced mitochondrial cell death in human cervical cancer cells. J Cell Physiol 2008;217:23-33. 


\section{AQ:6-7 Reprint requests}

596 AQ:8 Address requests for reprints to: Florent Toscano, MD, CNRS

597 AQ: 9 UMR5201, University of Lyon, Lyon F-69008, France. e-mail:
Acknowledgments

The authors thank their colleagues who provided reagents and technical supports, especially the Centre Commun d'Imagerie Laënnec for flow cytometry; Isabelle Durand for cell sorting; Cécile Vercherat and Martine Cordier-Bussat for the Bax immunoprecipitations; Serge Lebecque, Toufic Renno, and JeanJacques Diaz for discussions and intellectual inputs; and our colleagues in the laboratory for their restless support and encouragement.

Z.E.F. and F.T. contributed equally to this work.

\section{Conflicts of interest}

The authors disclose no conflicts.

\section{Funding}

Supported by the Ligue Nationale Contre Le Cancer (Comite du Rhône); by a from the French Ministry of Scientific Research (Z.E.F.); by Canceropole Lyon-Auvergne-Rhône-Alpes (F.T.); by a fellowship from the Ligue Nationale Contre le Cancer (G.J.); by grants from the Agence Nationale de la Recherche (ANR-06-JCJC-0103 and 07-PCV0031), and the European Community (ApopTrain Marie Curie RTN) (O.M.).
AQ:10 580

581

582

583

584 


\section{Titles and legends to supplemental figures}

Supplemental figure $1 \mathrm{HT} 29$ and V9P cells were incubated in the presence of TRAIL (10 $\mathrm{ng} / \mathrm{ml})$ for $2 \mathrm{~h}$. TRAIL was then removed and replaced with oxaliplatin $\left(\mathrm{IC}_{50}\right)$ for $6 \mathrm{~h}$. Apoptosis was determined by Annexin $\mathrm{V}$ staining followed by flow cytometry. Data reflected mean \pm SEM of three independently performed experiments.

Supplemental figure 2 TRAIL and oxaliplatin/TRAIL treatments induce Bid cleavages in HT29 and V9P cells. Cells were treated with oxaliplatin $\left(\mathrm{IC}_{50}, 2 \mathrm{~h}\right)$ then TRAIL $(10 \mathrm{ng} / \mathrm{ml}, 6 \mathrm{~h})$. Cleavage of Bid was assessed by Western blot by detection of reduced intensity of the 22 $\mathrm{kDa}$ band corresponding to full-length Bid. Similar results were obtained in three independently performed experiences

Supplemental figure 3 HT29 and V9P cancer cells were transfected using small interfering RNA (siRNA) pool consisting of four siRNAs specific for each protein. siRNAs were transfected at a final concentration of $100 \mathrm{nM}$. After $72 \mathrm{~h}$ of transfection, protein extracts were harvested and immunoblotted for the indicated antibodies to assess proteins silencing.

Supplemental figure 4 In vitro phosphatase treatment of protein extracts obtained from HT29 cells treated with oxaliplatin ( $\left.\mathrm{IC}_{50}, 2 \mathrm{~h}\right)$ then TRAIL $(10 \mathrm{ng} / \mathrm{ml}, 6 \mathrm{~h})$. Protein extracts $(50 \mu \mathrm{g})$ were incubated or not with 10 units of calf alkaline phosphatase, at $37^{\circ} \mathrm{C}$ for $30 \mathrm{~min}$.

Supplemental figure 5 HT29-EV, HT29-Bcl-xL.WT and HT29-Bcl-xL.S62D cells were treated with oxaliplatin $\left(\mathrm{IC}_{50}, 2 \mathrm{~h}\right)$ then TRAIL $(10 \mathrm{ng} / \mathrm{ml}, 4 \mathrm{~h})$ and subjected to immunoprecipitation with anti-Bax monoclonal antibody followed by immunoblot analysis with anti-Bcl-xL and anti-Bax antibodies.

Supplemental figure 6 HT29-EV, HT29-Bcl-xL.WT and HT29-Bcl-XL.S62D cells were treated with oxaliplatin $\left(\mathrm{IC}_{50}, 2 \mathrm{~h}\right)$ then TRAIL $(10 \mathrm{ng} / \mathrm{ml}, 4 \mathrm{~h})$ and subjected to immunoprecipitation with anti-Bcl-xL monoclonal antibody followed by immunoblot analysis with anti-Bcl-xL and anti-Bak antibodies.

Supplemental figure 7 HT29-EV, HT29-Bcl-xL.WT and HT29-Bcl-xL.S62D cells were treated with oxaliplatin $\left(\mathrm{IC}_{50}, 2 \mathrm{~h}\right)$ then TRAIL $(10 \mathrm{ng} / \mathrm{ml}, 4 \mathrm{~h})$ and subjected to immunoprecipitation with anti-Bax monoclonal antibody followed by immunoblot analysis with anti-Bax and anti-Bak antibodies. 


\section{Complete Materials and methods}

\section{Cell culture and drugs treatment}

Human colorectal cancer cell lines V9P (gift of Dr R. Hamelin, INSERM U762, Paris, France) and HT29 (from ATTCC) were grown in Dulbecco's modified Eagle's medium (Invitrogen) supplemented with $10 \%$ fetal bovine serum (FBS), $2 \mathrm{mM}$ glutamine, $10 \mu \mathrm{g} / \mathrm{ml}$ streptomycin and $10000 \mathrm{IU} / \mathrm{ml}$ penicillin in 5\% CO2 at $3^{\circ} \mathrm{C}$. Fres h solution of oxaliplatin (Eloxatin, Sanofi Aventis, $5 \mathrm{mg} / \mathrm{ml}$ ) was mixed in complete medium, added to adherent cells for $2 \mathrm{~h}$, then removed and replaced with fresh medium alone or with medium containing recombinant human TRAIL (Peprotech, 50 mg/ml; Fig. 1).

\section{Chemicals and antibodies}

JNK inhibitor (SP600125) was from Calbiochem. Annexin V-FITC and propidium iodide were from AbCys SA and Annexin V-APC was provided by Becton-Dikinson. RIPA Lysis Buffer Kit was provided by Santa Cruz Biotechnology. Primary antibodies for the following proteins were used at the designated dilutions: caspase-8 (1:1000), caspase-9 (1/1000), caspase-3 (1:1000), Bid (1:3000), Cytochrome c (1:3000), Cox IV (1:3000), Mcl-1 (1:1000), Bcl-2 (1:1000), Bcl-xL (1:2000), and phosphorylated JNK (1:1000) from Cell Signaling Technology, Bax (1:2000) and Bak (1:1000) from Epitomics, Bax 2D2 (1:500) and Serine 62 phosphorylated Bcl-xL (1:500) from Santa Cruz Biotechnology and anti-tubulin (1:300000) was obtained from Sigma.

\section{Annexin V staining and Flow cytometry}

Cells were stained with Annexin $\mathrm{V}$ and propidium iodide (PI), according to the manufacturer's instructions (AbCys SA). Briefly, cells were collected, washed with cold PBS, and suspended in $1 \mathrm{x}$ binding buffer provided by the kit. Next, cells were 
stained with $5 \mu$ Annexin V-FITC (for HT29 and V9P cells) or Annexin V-APC (for HT29-Bcl-XL.WT, HT29-Bcl-xL.S62D and HT29-EV cells) and $5 \mu \mathrm{IPI}$, and analyzed with a FACScanto II flow cytometer (BD Becton-Dickinson). Apoptotic cells percentage correspond to Annexin V (+) / PI (-) cells.

\section{Western blot analysis}

Cells were incubated for 30 min at $4^{\circ} \mathrm{C}$ in RIPA lysis buffer supplemented with PMSF, sodium orthovanadate and protease inhibitor cocktail solutions according to manufacturer's instructions (Santa Cruz Biotechnology). Equal amounts of proteins were loaded in each lane and separated by SDS-PAGE. Proteins were then transferred to a polyvinylidene difluoride membrane (PVDF) (Bio-Rad). Membrane was blocked with 5\% dry milk in TBS containing $0.1 \%$ Tween-20 and incubated with the primary antibody overnight at $4^{\circ} \mathrm{C}$ and with horseradish peroxidase-conjugated secondary antibody (Jackson ImmunoResearch Laboratories) for $1 \mathrm{~h}$ at room temperature. Proteins were visualized using chemiluminescence method (Covalab). Quantification was done using a Bio-Rad imaging system.

\section{Cell fractionation}

Mitochondrial and cytosolic fractions were prepared according to manufacturer's instructions (Pierce Biotechnology). Briefly, $2 \times 10^{7}$ cells were washed with PBS and then incubated with $0.5 \mathrm{ml}$ of mitochondrial isolation reagent $\mathrm{A}$ on ice for $10 \mathrm{~min}$. The cells were then lysed using a Dounce homogenizer by 20 strokes of the pestle. The lysate was transferred to a centrifuge tube, the volume adjusted to $0.7 \mathrm{ml}$, and then $0.35 \mathrm{ml}$ of $3 \mathrm{X}$-concentrated mitochondrial isolation reagent $\mathrm{B}$ was added. The sample was centrifugated at $700 \mathrm{~g}$ for 10 $\min$ to pellet the nuclei and the supernatant was centrifugated at $12,000 \mathrm{~g}$ for $15 \mathrm{~min}$ to obtain the cytosolic fraction in the supernatant and a mitochondrial pellet which was 
resuspended in storage buffer. Equal amounts of proteins were subjected to electrophoresis and immunoblot analysis as described above.

\section{Phosphatase treatment}

Cells were collected by scraping and lysed during 30 minutes at $4^{\circ} \mathrm{C}$ in RIPA lysis buffer supplemented with protease inhibitor cocktail (Santa Cruz Biotechnology). Lysates were clarified by centrifugation at $14,000 \mathrm{rpm}$ for 15 minutes at $4^{\circ} \mathrm{C}$, and divided into two equal aliquots. One aliquot was treated for 30 minutes at $37^{\circ} \mathrm{C}$ with 10 units of Calf Alkaline Phosphatase (Roche diagnostics) and one aliquot was mock-treated. Products were analyzed by immunobloting.

\section{Small interfering RNA transfection}

Small interfering RNA (siRNA) pool consisting of four siRNAs specific for each protein (ONTARGET plus smart pool siRNAs, Dharmacon RNAi Technologies) were used to knockdown caspase-8 (L-003466-00), caspase-3 (L-004307-00), caspase-9 (L-003309-00), Bax (L003308-01), Bak (L-003305-00) and Bcl-xL (L-003454-00). siRNAs were transfected at a final concentration of $100 \mathrm{nM}$ with DharmaFECT 4 following to the manufacturer's protocols. For JNK silencing we used SignalSilence SAPK/JNK siRNA kit (Cell Signaling Technology), which provided two specific siRNAs for JNK. Control cells were transfected with a non targeting siRNA (Dharmacon; D-001206-13-05). After $72 \mathrm{~h}$ of transfection at $100 \mathrm{nM}$, protein extracts were harvested and immunoblotted for the respective antibodies to assess proteins silencing.

\section{Construction of the Bcl-xL phosphorylation mutant}

Substitution of serine 62 to asparagine (S62D) or alanine (S62A) into the pMIGR-BcIXL-GFP retroviral plasmid was performed by PCR using the following specific oligonucleotides (Eurogentec): S62D sens: GGC-ACC-TGG-CAG-ACG-ACC-CCG-CGG-TGA-ATG. S62D antisens: CAT-TCA-CCG-CGG-GGT-CGT-CTG-CCA-GGT-GCC. S62A sens: GCA-CCT- 
GGC-AGA-CGC-CCC-CGC-GGT-GAA-T. S62A antisens: ATT-CAC-CGC-GGG-GGC-GTCTGC-CAG-GTG-C. Mutations in the plasmids were checked by DNA sequencing (Beckman Coulter Genomics).

\section{Retrovirus production and cell transduction}

Generation of retroviruses has been previously described (40). HT29 cells were transduced for 16 hours with viral supernatants containing polybrene $(8 \mathrm{mg} / \mathrm{ml})$, washed in phosphatebuffered saline, and cultured in complete medium. After transduction, GFP-positive cells were sorted using BD FACS vantage cell sorter.

\section{Immunoprecipitation}

Immunoprecipitation (IP) was carried out using the ExactaCruz product (SantaCruz Biotechnology), thereby bypassing any signal caused by $\lg G$ heavy chains and following manufacturer's guidelines. Briefly, Cells were lysed in CHAPS lysis buffer (150 mM sodium chloride, $10 \mathrm{mM}$ Hepes, $\mathrm{pH} 7.4$, and $1.0 \%$ Chaps) with freshly added proteases and Phosphatases inhibitors (Santa Cruz technology) and immunoprecipitated with ExactaCruz IP-matrix that was previously conjugated to anti-Bcl-xL antibody (Cell Signaling Technology), anti-Bax (Epitomics) or anti-active Bax 6A7 (BD Pharmingen). Resulting immune complexes were analyzed by western blot using appropriate primary antibodies and the secondary antibodies supplied by the ExactaCruz product.

\section{Statistical analysis}

All the data are summarized as mean \pm SEM of at least three separate experiments. Student's $t$-test was used to compare experimental with control groups. A P value $<0.05$ was considered statistically significant. 


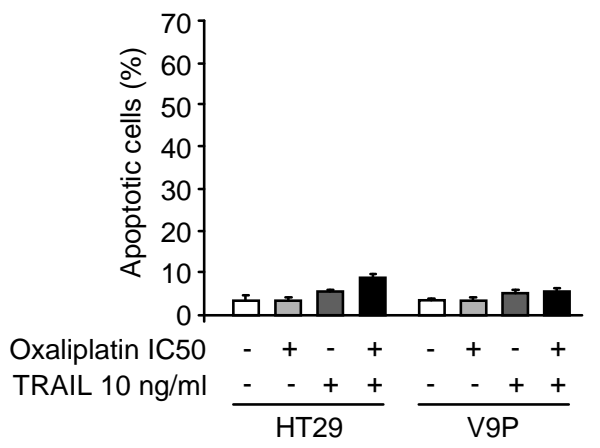

Supplemental figure 1 


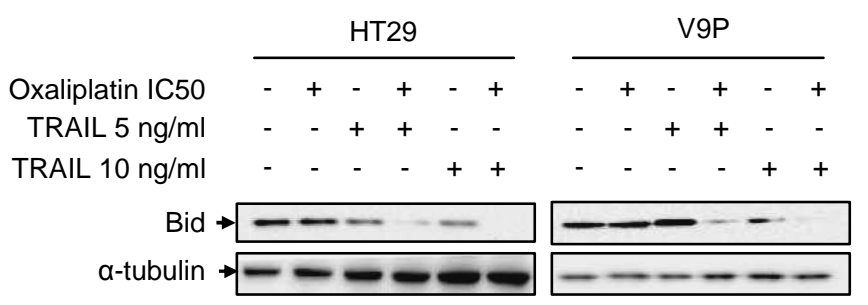

Supplemental figure 2 


\section{A}

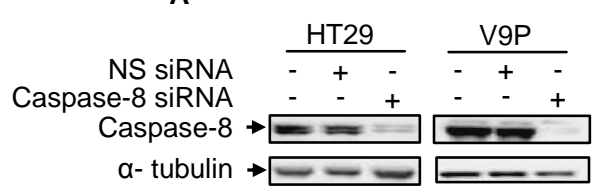

B

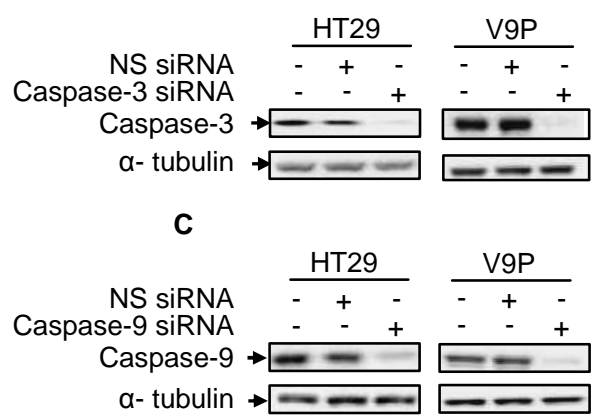

D

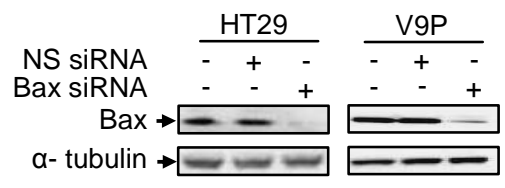

E

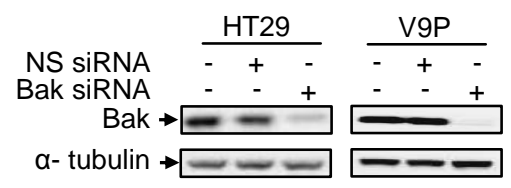

F

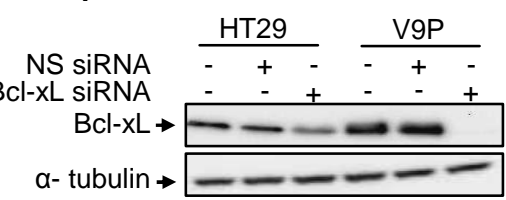

Supplemental figure 3 


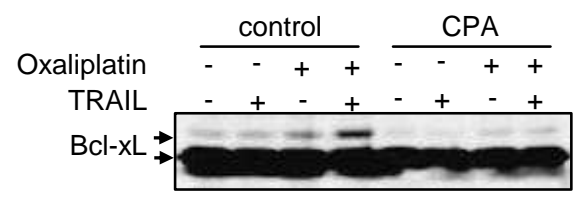

Supplemental figure 4 


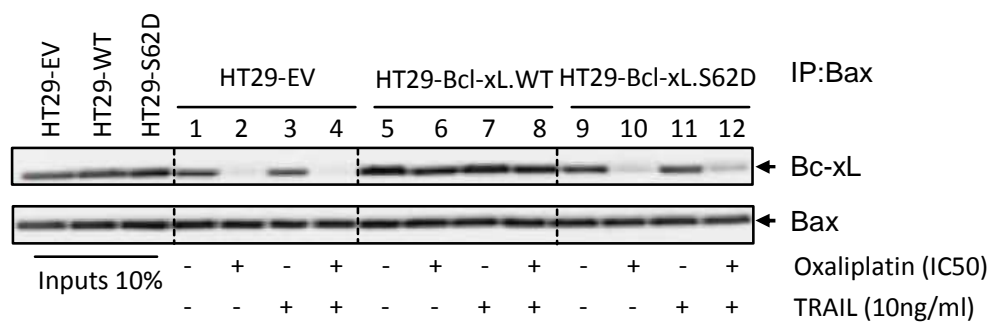

Supplemental figure 5 


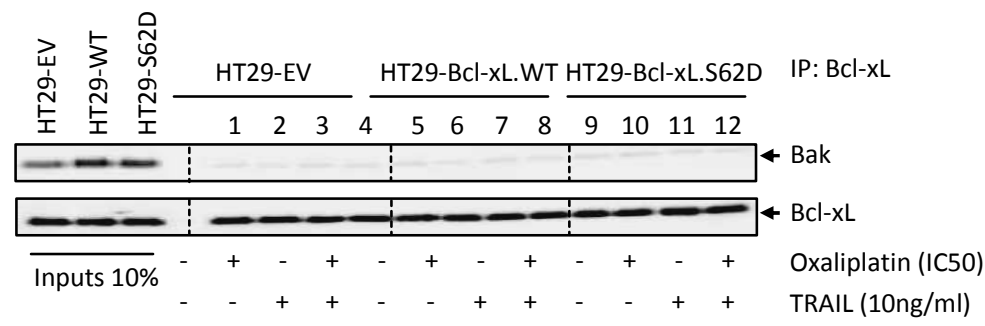

Supplemental figure 6 


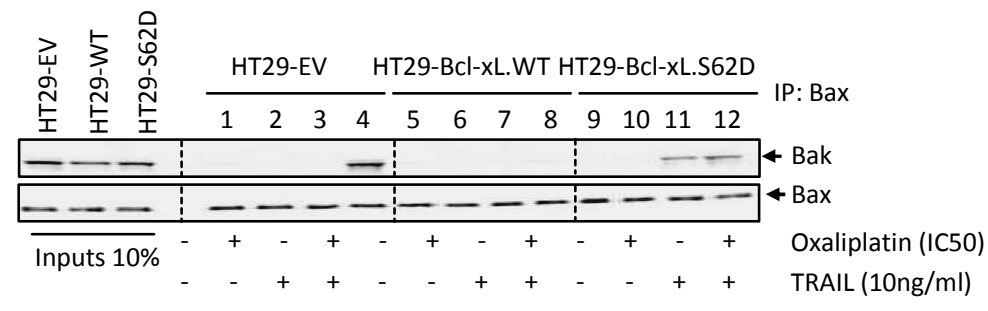

Supplemental figure 7 